\title{
A Controversial Assessment of Fitness to Fly After a Traumatic Brain Injury
}

\author{
Paola Verde; Anton Giulio Guadagno; Angelica D’Angelo; Roberto Vitalone; Antonella Di Vita; Laura Piccardi
}

\begin{abstract}
INTRODUCTION: After traumatic brain injury (TBI), cognitive, behavioral alterations and seizures frequently occur. Beside instrumental examinations, neuropsychological testing is the common clinical practice for detecting cognitive deficits. However, in highly skilled individuals, subtle changes with a large impact on fitness to fly may be neglected.

CASE REPORT: A 28-yr-old Italian Air Force pilot with almost 700 flying hours suffered a TBI. After 2 yr of cognitive retraining programs, as the neuropsychological evaluation executed in a public hospital was within the standards and repeated EEGs had all been normal, the pilot was allowed to resume flying duties. During the refresh flight training, he was not considered proficient for solo flight and was again referred to the Institute of Aerospace Medicine (IMAS), where, due to the absence of a neuropsychologist, the pilot was referred to a public hospital. Again, he was within the normal range and received a fitness to fly with limitations. Nevertheless, the flight instructors noticed the presence of cyclic errors. Consequently, he was sent for a third time to the IMAS, where the cooperation between a neuropsychologist and a flight surgeon allowed a tailored testing.
\end{abstract}

DISCUSSION: With a proper evaluation, the subject showed deficits in topographic visuospatial learning and in prospective memory. After $5 \mathrm{yr}$, he was finally declared permanently unfit to fly. Specific neuropsychological batteries, simulated flight tests, and aeromedical evaluations are described here.

KEYWORDS: head trauma, topographic memory, prospective memory, long-term memory, flight training, visuospatial learning, medical flight simulator test.

Verde P, Guadagno AG, D'Angelo A, Vitalone R, Di Vita A, Piccardi L. A controversial assessment of fitness to fly after a traumatic brain injury. Aerosp Med Hum Perform. 2022; 93(2):116-122.

N europsychological testing is a common clinical practice for detecting the presence of cognitive deficits following a brain lesion. Typically, it is performed with a battery approach, which investigates a broad range of cognitive domains, with more than one test per domain. It is crucial to determine financial compensation awards for people who are hurt in accidents. However, in some cases, especially when individuals are gifted or highly skilled, it may be difficult to detect subtle changes in cognitive functioning. Pilots need to deal with many different inputs that require interoperable working memory and attention (e.g., managing the visual data of speed and direction to maintain the ideal flight path). ${ }^{9,12}$

Indeed, spatial navigation itself is a complex cognitive ability that requires the integration of different sources of information, either online or offline. ${ }^{15,18}$ This highlights the idea that mental rotation and other cognitive skills, such as processing speed, working memory, directional judgements, and attention, are fundamental during aircraft navigation. Military pilots exhibit better topographic memory than nonpilots ${ }^{17}$ and are less affected than nonpilots by various forms of interference while performing topographic working memory tasks. ${ }^{16}$ Furthermore, judgement and decision-making that involve evaluation and prediction are essential skills critical to flight safety. Undoubtedly, pilots develop methods for superior perception,

\footnotetext{
From the Aerospace Medicine Department, Aerospace Test Division, Italian Air Force, Pratica di Mare, Rome, Italy; the Institute of Aerospace Medicine, Italian Air Force, Rome, Italy; the Departments of Human Neurosciences and Psychology, "Sapienza" University of Rome; and the Cognitive and Motor Rehabilitation and Neuroimaging Unit, IRCCS Fondazione Santa Lucia, Rome, Italy.

This manuscript was received for review in July 2021. It was accepted for publication in December 2021

Address correspondence to: Lt. Col. Paola Verde, M.D., Ph.D., Aerospace Medicine Department, Aerospace Test Division, Pratica di Mare, AFB, 00071 Pomezia (RM), Italy; paola.verde@aeronautica.difesa.it.

Copyright $\odot$ by The Authors.

This article is published Open Access under the CC-BY-NC license.

DOI: https://doi.org/10.3357/AMHP.5978.2022
} 
memory, and integration of information, which in turn are fundamental for quick and confident decisions during aerial navigation. ${ }^{1}$ Assessing fitness to fly in a pilot after a brain injury clearly requires the use of specific instruments, including a medical flight test/medical simulator test, to match the results obtained in a clinical setting with those of the flight world.

Here we describe a case of a helicopter pilot evaluated several times after a brain injury, including a neurocognitive assessment during a session in the helicopter simulator as a "last trial". After $5 \mathrm{yr}$, at the end of the assessment, the pilot was declared permanently unfit to fly due to his cognitive impairments despite the development of very good compensatory strategies to fill his mnemonic and attentional deficits. Indeed, only the use of specific neuropsychological tests associated with the flight simulator test has allowed examiners to detect subtle cognitive disorders in such a highly skilled individual. These people, even in the presence of impairments, can perform well in daily activities, but flight safety could be jeopardized at any stage. A flight test on the simulator was designed on the basis of the results obtained from the neuropsychological exam, and it identified the same deficits observed during the ground evaluation.

\section{CASE REPORT}

A 28-yr-old right-handed white Italian Air Force pilot with almost 700 total flying hours of flight time was injured in a motor vehicle crash, producing a right petrous ridge fracture with intraparenchymal hemorrhage (hemorrhagic contusion). He suffered from a moderate traumatic brain injury (TBI) with 24-h coma (Glasgow Coma Scale: 4), and $5 \mathrm{~d}$ of posttraumatic amnesia. He entered an intensive cognitive retraining program and, at the end of an appropriate recovery period of $2 \mathrm{yr}$ with repeated normal EEGs, the pilot was allowed to resume flying duties. In fact, despite the clinical history, he showed just psychomotor slowing and right neurosensory loss of hearing during extensive neurological exams. Unfortunately, the neuropsychological evaluation was executed in a national health system hospital due to the lack of neuropsychologists at the Institute of Aerospace Medicine and was within normal limits compared to the normative sample, which was not constituted by special populations (e.g., pilots) of high skill.

For these reasons, he was considered temporarily fit to fly with limitations. However, during the flight training for the recurrency flight, the instructors did not consider him proficient enough for solo flight. He was again referred to the Institute of Aerospace Medicine $1 \mathrm{yr}$ later to reconsider his fitness to fly. The pilot was referred once more to a public hospital, where he received a new neuropsychological examination. Nevertheless, he was administered a routine neuropsychological battery test aimed at detecting cognitive decline because the expert had underestimated the intrinsic abilities underlying the capability to fly; therefore, he neglected to assess specific cognitive processes. As the neuropsychological report considered him within the normal range of the general population, a new fitness to fly with limitations was issued by the Institute of Aerospace Medicine. Nevertheless, this positive outcome was in contrast with observations of the flight instructors, who constantly noticed that he made cyclic errors and omissions during the training; even when remarked on by the instructors, they were repeated one after another. Due to these new behavioral reports, he was sent again to the Institute of Aerospace Medicine to assess his fitness to fly. At this time, some experts in aerospace human factors were consulted. They proposed administering a proper aimed-neuropsychological battery to detect cognitive abilities involved in flight and a medical simulator flight test designed on the basis of the ground performance, as the pilot was considered temporarily unfit for flight. From these two combined evaluations, several cognitive deficits incompatible with flight emerged. Specifically, he showed episodic and prospective memory deficits occasionally accompanied by confabulations, learning difficulties, divided attention deficits, poor cognitive flexibility with perseverations, and mental slowing affecting decision-making.

\section{Memory Testing: Visuo-Spatial Memory}

The Corsi Block-Tapping Test. The Corsi Block-Tapping Test ${ }^{5,13}$ was administered to test working memory (WM), wherein the examiner taps a number of increasing blocks (starting from a 2to a 9-block sequence), and the subject then taps the block sequence in the same order. The score is the number of blocks in the longest sequence remembered correctly (block span). By means of the Corsi Block-Tapping Test, we assessed two other aspects of visuo-spatial long-term memory: learning and delayed recall. In learning, the pilot had to learn an 8-block sequence ${ }^{13}$ shown by the examiner. The learning criterion was reached if he reproduced the correct sequence three times in a row (maximum number of trials: 18). For delayed recall, the examiner asked him to reproduce the previously learned sequence $5 \mathrm{~min}$ later. The score was the number of blocks correctly reproduced (maximum score: 8 ). The pilot did not show any visuo-spatial WM deficits, but he was unable to learn the supra-span sequence even at the last presentation ( $18^{\text {th }}$ trial). Nevertheless, his performance was considered at the lower limits of the norm (see Table I). Although he apparently did not learn, he was able to recall the sequence correctly 5 min later.

\section{Attention and Memory Testing}

The Paced Auditory Serial Addition Test. The Paced Auditory Serial Addition Test (PASAT) ${ }^{4,8}$ assesses the capacity and rate of information processing and sustained and divided attention; it also involves WM and arithmetic capabilities. The subject is presented with a long oral sequence of digits and he must sum each number with the next and say the answer out loud continuously throughout the sequence. This requires that, for each answer, the subject keeps in memory the last number heard and then adds it to the next and simultaneously inhibits the memory of the answer given to distinguish it from the sequence of numbers on which it is called to operate [e.g., for 4 and 6, the pilot had to say $10(4+6)$, and if the third digit was 3 , the pilot had to say $9(6+3)]$. 
Table I. Test Results.

\begin{tabular}{|c|c|c|}
\hline TEST & RAW SCORE & \\
\hline $\begin{array}{l}\text { Modified Five Point } \\
\text { Test (MFPT; } \\
\text { Cattellani et al..3) }\end{array}$ & UDs $=19$ & SS $=0$ \\
\hline $\begin{array}{l}\text { Paced Auditory } \\
\text { Serial Addition } \\
\text { Test (PASAT; } \\
\text { Ciaramelli et al. }{ }^{4} \text { ) }\end{array}$ & $\begin{array}{l}\text { ISI } 4000=11 \\
\text { ISI } 3000=21 \\
\text { ISI } 2600=15 \\
\text { ISI } 2200=12 \\
\text { ISI } 1800=31\end{array}$ & $\begin{array}{l}\text { Cut-off }=6 \\
\text { Cut-off }=8 \\
\text { Cut-off }=7 \\
\text { Cut-off }=8 \\
\text { Cut-off }=11\end{array}$ \\
\hline $\begin{array}{l}\text { Rivermead } \\
\text { Behavioral } \\
\text { Memory Test } \\
\text { (RBMT-3; Wilson } \\
\text { et al. }{ }^{19} \text { ) }\end{array}$ & 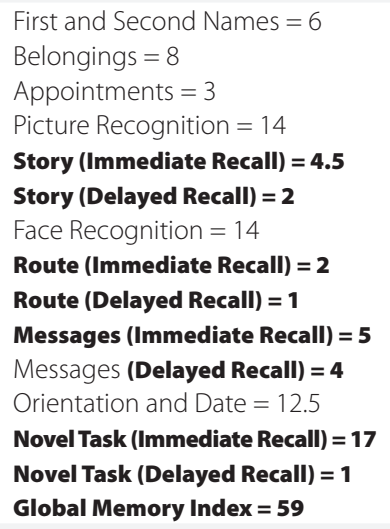 & $\begin{array}{l}\mathrm{SC}=11 \\
\mathrm{SC}=11 \\
\mathrm{SC}=9 \\
\mathrm{SC}=7 \\
\mathbf{S C}=\mathbf{3} \\
\mathbf{S C}=\mathbf{2} \\
\mathrm{SC}=11 \\
\mathbf{S C}=\mathbf{1} \\
\mathbf{S C}=\mathbf{1} \\
\mathrm{SC}=6 \\
\mathrm{SC}=\mathbf{1} \\
\mathrm{SC}=9 \\
\mathbf{S C}=\mathbf{1} \\
\mathbf{S C}=\mathbf{1} \\
\mathbf{P R}=\mathbf{3}\end{array}$ \\
\hline $\begin{array}{l}\text { Corsi Block-Tapping } \\
\text { Test (CBT; } \\
\text { Piccardi } \\
\left.\text { et al. }{ }^{13}\right)\end{array}$ & $\begin{array}{l}\text { Span }= \\
\text { Learning }=69 \\
\text { Delayed Recall }=8\end{array}$ & $\begin{array}{l}Z \text { score }=-1.58 \\
Z \text { score }=0.66\end{array}$ \\
\hline 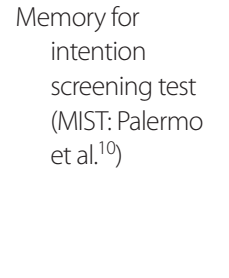 & $\begin{array}{l}\mathbf{2}-\mathbf{m i n} \text { delay }=\mathbf{5} \\
15-\text { min delay }=6 \\
\text { Time-based cues }=\mathbf{4} \\
\text { Event-based cues }=7 \\
\text { Verbal response }=6 \\
\text { Physical response }=5 \\
\text { Summary score }=\mathbf{1 9} \\
24-\mathrm{h} \text { task }=2\end{array}$ & $\begin{array}{l}\text { Crawford_P }=\mathbf{0 . 0 0} \\
\text { Crawford_P }=0.44 \\
\text { Crawford_P }=\mathbf{0 . 0 1} \\
\text { Crawford_P}=0.44 \\
\text { Crawford_P }=0.08 \\
\text { Crawford_P}=0.11 \\
\text { Crawford_P }=\mathbf{0 . 0 0} \\
\text { Crawford_P }=0.22\end{array}$ \\
\hline
\end{tabular}

Impaired performances are indicated in bold.

UDs = Unique designs; SS = standard score from 1 to 4 in the normal range ( 0 is pathological); $\mid \mathrm{SI}$ = interstimulus interval; SC = scaled score; $\mathrm{PR}=$ percentile rank.

This kind of task then includes temporarily maintaining cognitive processing and the continuous updating of information in working memory. The PASAT was administered 5 times at different interstimulus rates $(4.0,3.0,2.6,2.2$, and $1.8 \mathrm{~s})$. We considered mistaken answers and omissions. When WM was assessed under conditions of divided and sustained attention load, the patient presented a deficient performance (see Table I), especially in the longer time intervals of presentation ( 4.0 and $3.0 \mathrm{~s}$ ).

\section{Prospective Memory Assessment}

The Memory for Intentions Screening Test. The Memory for Intentions Screening Test $(\mathrm{MIST})^{14}$ for Italian populations ${ }^{10,11}$ requires performing prospective memory tasks while engaging in a word search puzzle to prevent overt rehearsal of the prescribed intentions. It includes the following variables:

- Length of the delay interval that is either short (2 min) or long (15 min).

- Types of cues that are either time-based or event-based.

- Response modality that is either a verbal or a physical response.
The MIST provides a summary score, ranging from 0 to 48 , and includes a three-choice recognition test (MIST-Recognition: maximum score 8). Finally, there was a 24 -h delay trial (MIST$24 \mathrm{~h}$ ) in which the participant was asked to call or text the examiner after $24 \mathrm{~h}$, reporting how many hours he slept the night after the test (score range: $0-2$ ).

Taking into account that Italian normative data ${ }^{10}$ are not divided into an age basis, to characterize the neuropsychological profile of the pilot, his performance was compared with a normative group through BTD_Cov.exe, ${ }^{6}$ which allows an assessment of the performance covarying for age. The results (Table I) showed that the pilot had a lower performance than his age-matched control group, despite his ability to use compensatory strategies (i.e., taking notes about the task). Upon analysis, the single variables revealed a deficit of prospective memory within 2 min (a very short interval). Moreover, the pilot showed a tendency to execute tasks before the required time and sometimes he did not respond with the right task at the right time. In fulfilling a questionnaire about his performance, he was aware of having made some errors. He succeeded in performing the task after $24 \mathrm{~h}$ (making a phone call to the medical department) due to his compensatory strategy of taking notes about the event. Moreover, in this case, the task was not complicated by taking in mind several tasks to carry out at the same time.

Rivermead Behavioral Memory Test. The Rivermead Behavioral Memory Test-third edition ${ }^{19}$ contains 10 subtests to assess different memory components: verbal (i.e., remembering the name of two people, immediate and delayed story recall), visual (i.e., face and line drawing recognition), spatial (i.e., immediate and delayed recall of a short route, immediate and delayed recall of puzzle pieces in order within a template), and perspective memory (i.e., remembering to ask for two personal belongings, asking questions as soon as an alarm rings). In addition to the raw scores on the subtests, the Global Memory Index was computed as an overall memory performance measure. The pilot failed in several subtests; specifically, he showed an episodic memory deficit characterized by confabulations in the attempt to reconstruct the event to recall. He also showed a deficit in learning the sequence of the actions as well as a deficit in topographic memory (see Table I).

\section{Cognitive Flexibility Testing}

The Modified Five-Point Task. The Modified Five-Point Task ${ }^{3}$ consists of a sheet with 40 dot matrices $(3 \mathrm{~cm} \times 2 \mathrm{~cm})$ arranged in an array of eight rows and five columns, each consisting of a fixed pattern identical to the five-dot arrangement on dice. The pilot was asked to connect two or more dots by always using one or more straight lines. He was also informed that the goal of the task was to generate as many unique designs as possible without replicating any drawings. The number of unique designs was calculated by subtracting the number of repeated/perseverative designs and rule-breaking errors from the number of designs overall. The pilot showed a deficient performance in this task (see Table I). 
Table II. Simulation Set Up—Briefing Guide Flight Simulator TH-500B.

\begin{tabular}{lc}
\hline SIMULATION SET UP & \\
\hline Apron & $\mathrm{G}$ \\
Runway & 34 \\
Engine & On \\
All radio/nav & On \\
Step Out & \\
Meteorological condition & Latina BLU \\
Alternate airdrome & SAMBA 73 \\
Chase of solo pilot & Tower and Approach \\
Air traffic control & \\
Mission Overview & \\
Radio call ready for departure with Tower & \\
Takeoff for pattern (3-4 pattern, Instructor & \\
judgement) & \\
Downwind for training helipad & \\
Go-around on final, not landing & \\
Normal and steep approach & \\
At the third approach go-around for 2 e 3 & Sperentino $2000 \mathrm{ft}$ \\
\hline lower (north of Frosinone airport) & \\
Crossing 2000 ft radio change from Tower to & \\
Approach frequency & \\
Radio call entering in the area & \\
Flight exercise in area: 2 turns of 360 & \\
and $45^{\circ}$, quick stop & \\
After these exercises: radio call for normal o & \\
peration & \\
Autorotation with go-around & \\
Approach on a field with go-around & \\
Return to base & \\
Downwind for training helipad with go-around & \\
Normal and steep approach & \\
Full stop landing on the runway & \\
Parameters for Procedures and Maneuvers & \\
Pattern & \\
Pattern & \\
Normal approach & \\
Steep approach & \\
Climb & \\
Leveling & \\
Leveling & \\
Autorotation & \\
Entry point for pattern & \\
\hline
\end{tabular}

Callsign SAMBA21; time of day 11 a.m. June 21; short checklist and in-flight guide: Italian Air Force Helicopter Training School $72^{\text {nd }}$ Wing.

Medical Simulator Flight Test. The Medical Simulator Flight Test was designed in accordance with the neuropsychological results carried out on the ground. This test was conducted on a $\mathrm{TH}-500 \mathrm{~B}$, a rotary wing fixed-based simulator. The mission profile contained a selection of visual flight maneuvers scheduled for the training program of the military pilot license (helicopter track) for the Italian Air Force trainees. Due to the particular kind of mission, the assessment of the single maneuver was "no grade", while the examiner briefly commented on the pilot's general performance and mission itself. The disadvantages are: the simulation suffers from discrepancies with reality, especially in perceiving the visual depth in flight phases near to the ground (below $50 \mathrm{ft}$ ), and taxiing maneuvers, final approaches, and autorotation have to abruptly end.

The advantages are: the mission profile flown on the simulator allows assessment of the intrinsic abilities of a pilot qualified
Table III. Event Timeline.

\begin{tabular}{ll}
\hline TIME & \multicolumn{1}{c}{ EVENT } \\
\hline$-00: 30$ & Briefing \\
00:00 & Radio call Frosinone Tower and takeoff \\
00:01 & Handling exercise on simulator, approaches, and go-around \\
00:10 & Takeoff to reach the working area \\
00:11 & Radio call with Frosinone Approach \\
00:15 & Reaching the working area and exercises \\
00:20 & Radio call every three exercises \\
00:25 & Radio call for normal operations \\
00:25 & Autorotation ingress and going around at 1500 ft \\
$00: 26$ & Approach radio call about emergency at solo SAMBA 73 \\
$00: 27$ & Recognition for approaching out of field, approach, and \\
& going-around \\
$00: 37$ & Approaching Air Traffic Control radio call about airport status, \\
& due to the emergency, landing is not feasible \\
$00: 50$ & Navigation toward alternate airport \\
$01: 00$ & Landing at Latina Airport \\
\hline
\end{tabular}

on the rotary wing and the decision-making capabilities in managing nonscheduled events. The presence of the instructor pilot (IP) allows mitigation of the effects of possible loss of orientation. The presence of an air traffic controller allows correct simulation of the dynamics in managing the air space and related communications. (For the simulator setup, event timeline, and mission bullets, see Table II, Table III, and Table IV).

During the briefing, the pilot was unable to maintain attention since paper was not available on which to take notes for his compensatory strategy to recall information in the subsequent phase of the mission on the simulator. On the basis of the mission, the committee composed by the IP, a neuropsychologist, and an aerospace human factors expert noted that there was a failure to maintain information as well as cues that were not recorded by the pilot. Moreover, the committee reported the following observations: the procedures were correctly performed by means of an active use of compensatory strategies that were so well developed that any other pilot could encounter difficulties in reading notes on the kneeboard and flying the mission in a nauseogenic simulator environment. An example of failure is given by the report of the positions: when the pilot was not able to write during the briefing, he did not report the position, jumping to the following position that was in his notes. His performance during the simulation was similar to that of the perspective memory ground evaluation (MIST), in which he did not make the right event at the right moment, or he completely omitted the event.

The next day, at the same time, an identical mission was flown involving the same subjects. The pilot was using the same notes taken the day before and the same lapses and errors were carried out except for the IFF code that was correct, perhaps due to the right reading.

The salient aspect in a global evaluation is that the pilot had lost the capability to remember and lost his learning capability; therefore, perseverations were unavoidable. Thus, he could perform the same circuit one hundred times, producing the same error one hundred times. Any pilot will strictly follow the checklist the first time he flies at a new airport; nevertheless, after a few times, he will have no need to consult any written 
Table IV. Mission Bullets.

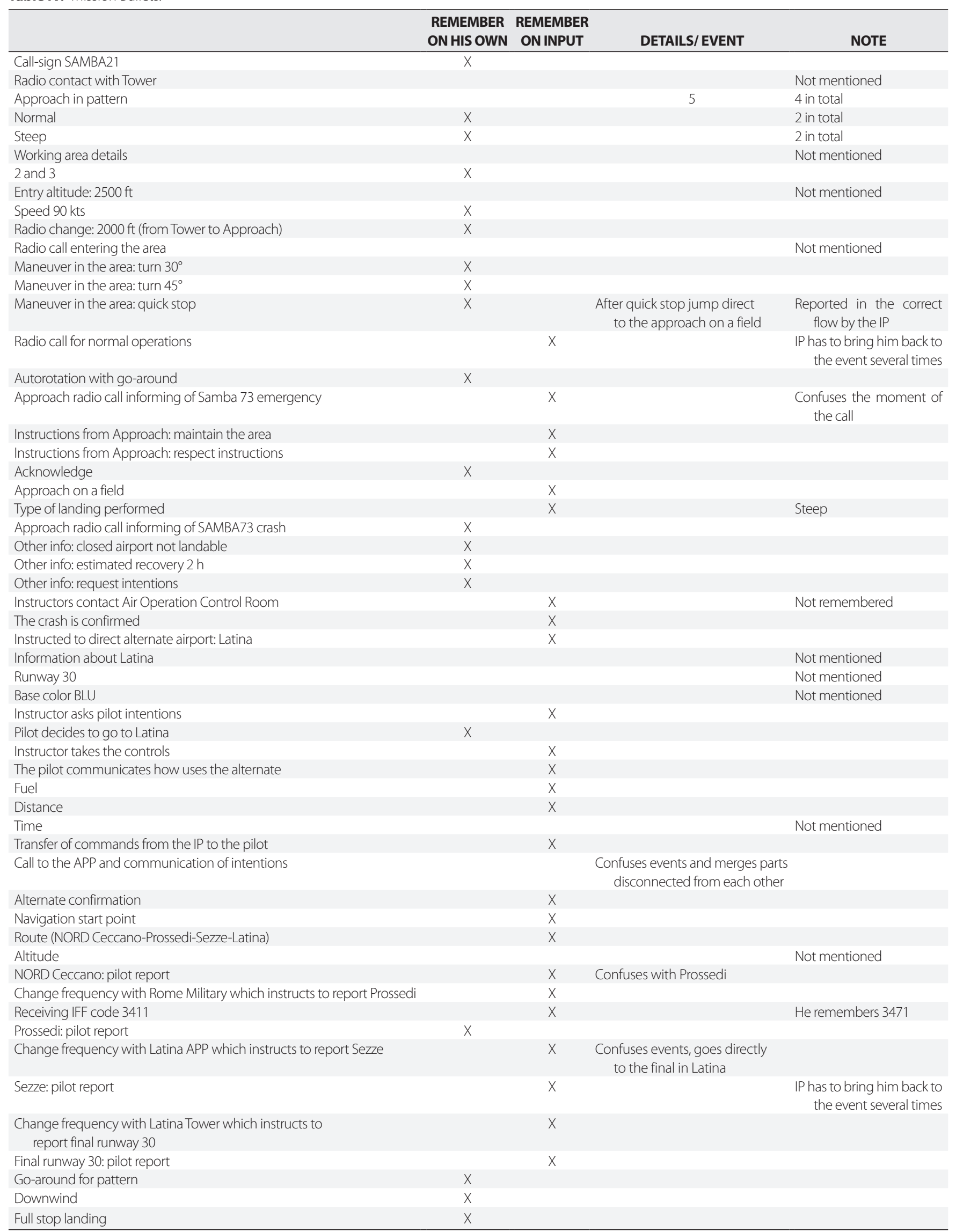

IP: Instructor pilot. 
notes. During both missions, the pilot showed a slowing in actions as well as an extreme slowness in information processing associated with a difficulty in rescheduling the flight plan strategies, with a tendency to propose perseverant and ineffective solutions (i.e., during the mission, despite being invited to land in the alternate heliport, he continued to maintain position). The IP referred to observing an extreme cognitive rigidity that resulted in not accepting any change. When an element of interference was introduced into the flight plan (i.e., go to the alternate heliport due to the closure of the main heliport), working memory deficits clearly emerged due to the attentive load as well as his divided attention difficulty. The deficit of prospective memory and divided attention was confirmed on the final approach when, due to the lack of a report "on final", Latina Tower had to intervene to confirm the activity. In the debriefing phase, as reported by the IP, the pilot did not correctly remember details of a just flown mission, confirming the presence of an episodic memory deficit enriched by confabulations.

\section{DISCUSSION}

Because routine clinical practice is not designed to investigate the pathology in highly skilled individuals who carry out specific tasks, we underline the importance of combining clinical competences with specific knowledge of the performance required in the aerospace field. Indeed, to better investigate the real capability of an expert pilot with a previous TBI, we used the results obtained from ground testing, investigating specific flight competencies, to simulate a flight mission where real deficits that may not be evident in daily life or are very well compensated for emerged, as in this case. Only by means of a neuropsychological evaluation designed for pilots' competencies did we have the opportunity to design a specific flight mission involving the same cognitive impairments evidenced on the ground. It is not taken for granted, in fact, that the results on the ground reflect the performance in flight. In our case, only the combination of these two evaluations allowed us to characterize the cognitive profile of the pilot and to reach a final medical legal conclusion of Duties Not to Include Flying.

TBI is one of the most challenging aeromedical certification issues due to the potential for subtle and sudden incapacitation and for the variable timing and degree of eventual recovery. Too often, head injured aircrew, more frequently involving private pilots with mild TBI, are assessed by using the neuropsychological standardized battery from the general population, in which the highly demanding tasks of flying duties are not taken into consideration or, as in this case, cognitive failures of highly skilled individuals are not detected.

Pilots are, in general, a very high functioning population. Consequently, a normal performance on neuropsychological tests (compared to national standardization samples) may represent a decline from the premorbid condition. A psychologist unfamiliar with typical aircrew performance might have concluded after the first evaluations that there was no impairment in ability and recommended a return to flying. Moreover, reduced functioning as a result of a head injury is selective and the skills most affected are often critical to competent aviators, such as the rapid processing of information and working memory. Finally, a global score on neuropsychological assessment may be unhelpful, as it incorporates the results of several subtests, some of which are resistant and others are sensitive to cortical insult; therefore, a deficit may be masked.

In conclusion, only by means of specific testing on the ground and in flight (simulated) were we able to demonstrate that this pilot, despite a preserved working memory, was suffering from some deficits in topographic and visuospatial learning and an impairment in long-term memory as well as prospective memory. His performance in these tasks compared with that of other military pilots was clearly impaired. After several years, the pilot was finally declared permanently unfit to fly. Neuropsychological testing is complex and expensive, but in some cases, it is absolutely needed and can certainly be improved by specific adaptations for defining aviation-related abilities. ${ }^{7}$

\section{ACKNOWLEDGMENTS}

Financial Disclosure Statement: The authors have no competing interests to declare.

Authors and Affiliations: Paola Verde, M.D., Ph.D., and Roberto Vitalone, FN, Aerospace Medicine Department, Aerospace Test Division, Italian Air Force, Pratica di Mare, Rome, Italy; Anton Giulio Guadagno, M.D., and Angelica D’Angelo, Psy., Institute of Aerospace Medicine, Italian Air Force, Rome, Italy; Antonella Di Vita, Psy., Ph.D., Department of Human Neurosciences, and Laura Piccardi, Ph.D., Department of Psychology, "Sapienza" University of Rome, Rome, Italy; and Laura Piccardi, Cognitive and Motor Rehabilitation and Neuroimaging Unit, IRCCS Fondazione Santa Lucia, Rome, Italy.

\section{REFERENCES}

1. Adams RJ, Ericsson AE. Introduction to cognitive processes of expert pilots. Hum Perf Extrem Environ. 2000; 5(1):44-62.

2. Annegers JF, Hauster WA, Coan SP, Rocca WA. A population-based study of seizures after traumatic brain injuries. N Engl J Med. 1998; 338(1):20-24.

3. Cattelani R, Dal Sasso F, Corsini D, Posteraro L. The Modified Five-Point Test: normative data for a sample of Italian healthy adults aged 16-60. Neurol Sci. 2011; 32(4):595-601.

4. Ciaramelli E, Serino A, Di Santantonio A, Ládavas E. Central executive system impairment in traumatic brain injury. Brain Cogn. 2006; 60(2):198-199.

5. Corsi PM. Human memory and the medial temporal region of the brain. Dissertation Abstracts International. 1973; 34(2-B):891. University micro-lms No. AA105-77717.

6. Crawford JR, Garthwaite PH, Ryan K. Comparing a single case to a control sample: testing for neuropsychological deficits and dissociations in the presence of covariates. Cortex. 2011; 47(10):1166-1178.

7. Fiedler E, Orme DR, Mills W. Assessment of head-injured aircrew: comparison of FAA and USAF procedures. Washington (DC): U.S. Department of Transportation, Federal Aviation Administration, Office of Aerospace Medicine; July 2001.

8. Gronwall DM. Paced auditory serial-addition task: a measure of recovery from concussion. Percept Mot Skills. 1977; 44(2):367-373.

9. Kennedy Q, Taylor JL, Reade G, Yesavage JA. Age and expertise effects in aviation decision-making and flight control in a flight simulator. Aviat Space Environ Med. 2010; 81(5):489-497. 
10. Palermo L, Cinelli MC, Piccardi L, Ciurli P, Incoccia C, et al. Women outperform men in remembering to remember. Q J Exp Psychol (Hove). 2016; 69(1):65-74.

11. Palermo L, Cinelli MC, Piccardi L, De Felice S, Ciurli P, et al. Cognitive functions underlying prospective memory deficits: a study on traumatic brain injury. Appl Neuropsychol Adult. 2020; 27(2):158-172.

12. Pérès $M$, Van De Moortele PF, Pierard C, Lehericy $S$, Satabin $P$, et al. Functional magnetic resonance imaging of mental strategy in a simulated aviation performance task. Aviat Space Environ Med. 2000; 71(12) 1218-1231.

13. Piccardi L, Bianchini F, Argento O, De Nigris A, Maialetti A, et al. The Walking Corsi Test (WalCT): standardization of the topographical memory test in an Italian population. Neurol Sci. 2013; 34(6):971-978.

14. Raskin SA. Memory for intentions screening test [abstract]. J Int Neuropsychol Soc. 2004; 10:110.
15. Verde P, Angelino G, Piccolo F, Carrozzo P, Bottiglieri A, et al. Spatial orientation and directional judgments in pilots vs. non-pilots. Aerosp Med Hum Perform. 2018; 89(10):857-862.

16. Verde P, Boccia M, Colangeli S, Barbetti S, Nori R, et al. Domain-specific interference tests on navigational working memory in military pilots. Aerosp Med Hum Perform. 2016; 87(6):528-533.

17. Verde P, Piccardi L, Bianchini F, Guariglia C, Carrozzo P, et al. Gender differences in navigational memory: pilots vs. non-pilots. Aerosp Med Hum Perform. 2015; 86(2):103-111.

18. Verde P, Piccardi L, Bianchini F, Trivelloni P, Guariglia C, et al. Gender effects on mental rotation in pilots vs. non-pilots. Aviat Space Environ Med. 2013; 84(7):726-729.

19. Wilson BA, Greenfield E, Clare L, Baddeley A, Cockburn J, et al. RBMT-3 Rivermead Behavioural Memory Test, Third Edition. Firenze: Giunti OS; 2013. 